\title{
TUTELA JURÍDICA DOS DIREITOS SOCIAIS EM FORMAÇÃO NA PEC DA "NOVA PREVIDÊNCIA": UMA ANÁLISE DO TRATAMENTO CONFERIDO ÀS APOSENTADORIAS VOLUNTÁRIAS
}

LEGAL PROTECTION OF SOCIAL RIGHTS IN FORMATION IN THE "NEW WELFARE" BILL: AN ANALYSIS OF THE TREATMENT GIVEN TO VOLUNTARY RETIREMENT

TUTELA JURIDICA DE LOS DERECHOS SOCIALES EN FORMACIÓN EN LA PEC DE LA "NUEVA JUBILACIÓN": UN ANÁLISIS DEL TRATAMIENTO CONFERIDO A LAS JUBILACIONES VOLUNTARIAS

Licença CC BY:

Artigo distribuído sob os termos Creative Commons, permite uso e distribuição irrestrita em qualquer meio desde que o autor credite a fonte original.

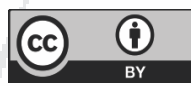

\section{José Antonio Savaris ${ }^{1}$}

\section{Victor Roberto Corrêa de Souza²}

Resumo: O presente trabalho se destina a analisar, no contexto da Proposta de Emenda Constitucional 006/2019, que projeta promover a mais nova reforma nos regimes públicos de previdência, a necessidade de se conferir a tutela jurídica aos direitos sociais em formação, com ênfase para as aposentadorias voluntárias, cujos critérios de elegibilidade são apenas cumpridos após décadas de contribuição. Adotando o método indutivo, identifica a insuficiência de institutos constitucionais, como o direito adquirido, para proteger, em termos de segurança jurídica, os trabalhadores que são afetados por alterações normativas mais restritivas. Identifica as alterações paramétricas que se pretende estabelecer com a "Nova Previdência", analisando as novas regras transitórias oferecidas na perspectiva da necessária proteção da confiança dos trabalhadores filiados aos sistemas previdenciários, apontando violações à segurança jurídica. Partindo de apontamentos dogmáticos relativos à proteção constitucional da segurança jurídica, critica a conservadora tese ainda prestigiada pela Suprema Corte brasileira, segundo a qual inexiste direito adquirido a regime jurídico e, por consequência, nenhuma tutela jurídica pode ser conferida aos direitos em formação, por ela considerados como meras expectativas de direito.

1 Doutor em Direito (USP). Mestre em Direito Econômico e Social (PUC-PR). Docente Permanente do Programa de Pós-Graduação Stricto Sensu da UNIVALI. Juiz Federal.

2 Doutor em Sociologia e Direito e Mestre em Justiça Administrativa, pela Universidade Federal Fluminense. Juiz Federal. 
Palavras-chave: Direitos Sociais; Reforma Previdenciária; Segurança Jurídica; Proteção da Confiança; Direitos Adquiridos; Direitos em Formação.

Abstract: In the context of Proposed Constitutional Amendment 006/2019, which aims to promote the newest reform in public pension systems, this work analyzes the need to give legal protection to social rights in formation, with emphasis on voluntary pensions, whose eligibility criteria are only met after decades of contribution. Adopting the inductive method, it identifies the inadequacy of constitutional institutes, such as acquired law, to protect and give legal certainty to workers who are affected by more restrictive regulatory changes. It identifies the parametric changes to be instituted by the "New Welfare", analyzing the new transitional rules offered from the perspective of the necessary protection of the trust of workers affiliated to social security systems, and pointing to violations of legal certainty. Based on some dogmatic notes concerning the constitutional protection of legal certainty, it criticizes the conservative thesis that is still favored by the Brazilian Supreme Court, whereby there is no acquired right to the legal system and, consequently, no legal protection can be conferred on rights in formation, which it regards as mere expectations of law.

Keywords: Social Rights; Social Security Reform; Legal Security; Protection of Trust; Acquired Rights; Rights in Formation.

Resumen: El presente trabajo se destina a analizar, en el contexto de la Propuesta de Enmienda Constitucional 006/2019, que proyecta promover la nueva reforma en los regímenes públicos de la jubilación, la necesidad de conferir la tutela jurídica a los derechos sociales en formación, con énfasis para las jubilaciones voluntarias, cuyos criterios de elegibilidad son apenas cumplidos después de décadas de contribución. Adoptando el método inductivo, identifica la insuficiencia de institutos constitucionales, como el derecho adquirido, para proteger, en términos de seguridad jurídica, a los trabajadores que son afectados por alteraciones normativas más restrictivas. Identifica las alteraciones paramétricas que se pretende establecer con la "Nueva Jubilación", analizando las nuevas reglas transitorias ofrecidas en la perspectiva de la necesaria protección de la confianza de los trabajadores afiliados a los sistemas jubilatorios, apuntando violaciones a la seguridad jurídica. Partiendo de apuntes dogmáticos relativos a la protección constitucional de la seguridad jurídica, critica a la conservadora tesis todavía prestigiada por la Suprema Corte brasileña, según la cual inexiste derecho adquirido al régimen jurídico y, por consecuencia, ninguna tutela jurídica puede ser conferida a los derechos en formación, por ser considerados como meras expectativas de derecho.

Palabras-clave: Derechos Sociales; Reforma Jubilatoria; Seguranza Jurídica; Protección de Confianza; Derechos Adquiridos; Derechos en Formación.

\section{INTRODUÇÃO}

É possível considerar que a segurança jurídica deva ser respeitada apenas de acordo com fatos pretéritos já concluídos? É possível considerar a segurança sem qualquer alusão ao comportamento do Estado, avaliando apenas comportamentos individuais? Apenas medidas objetivas, como o momento do ato praticado ou sua duração, permitem conferir proteção à segurança jurídica? 
Alguns institutos jurídicos foram consagrados pela dogmática constitucional há algum tempo, visando à proteção da segurança jurídica das pessoas. Por exemplo, a vedação à integral retroatividade das leis, para algumas relações entre Estado e indivíduo, bem como o direito adquirido, o ato jurídico perfeito, a coisa julgada, a prescrição e a decadência fazem parte dessa história legislativa. A resposta às três perguntas supra formuladas poderá ajudar a confirmar a hipótese: esses institutos são insuficientes à proteção da segurança jurídica do indivíduo diante do Estado na esfera dos direitos sociais.

E essa insuficiência é sobressaltada em tempos de uma Nova Previdência, em que se discute mais uma Reforma Constitucional do direito previdenciário brasileiro (por meio da PEC 6/2019), com pretensões de redução dos gastos públicos com a proteção social do cidadão brasileiro, em face dos riscos da vida moderna. Pretende o Constituinte Reformador impor redução do nível de proteção (diminuição de valores de benefícios) e maior dificuldade para a concessão de prestações sociais, com a alteração dos limites e requisitos objetivos para obtenção de aposentadorias, pensões e benefícios outros, o que induz a algumas dificuldades de apreensão da reforma, especialmente sob a ótica da segurança jurídica. Mas, afinal, como a Nova Previdência protegerá a confiança daquele cidadão, daquela brasileira que se encontrava na expectativa legítima de se aposentar, conforme seu planejamento previdenciário e autorizado pelo ordenamento legislativo e constitucional em vigor, em 2 ou 4 anos?

O presente trabalho, valendo-se do método indutivo, se dedica a analisar criticamente o grau de segurança jurídica conferido aos trabalhadores filiados aos regimes públicos de previdência diante da implementação de medidas regressivas normativas, como a que se afigura a Proposta de Emenda Constitucional 006/2019, cujo propósito é promover uma nova reforma constitucional previdenciária.

O princípio da proteção da confiança, nessa hipótese, pode ir além dos institutos de proteção da segurança jurídica já consagrados, como se verá ao analisar parte do texto da Reforma apresentada. 


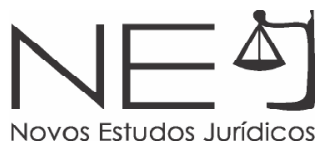

Na primeira seção, busca-se identificar a importância da proteção jurídica concedida aos direitos adquiridos no contexto do Estado de Direito, apontandose os termos em que é compreendido como segurança do cidadão contra alterações normativas estatais. Nessa mesma parte, aponta-se sua insuficiência para a proteção de posições jurídicas consolidadas no passado, mas que ainda não consubstanciam situação de aquisição de direito social.

Na seção seguinte, aprofunda-se a problemática concernente à necessidade de tutela jurídica dos direitos em formação, com vistas à reafirmação da segurança jurídica. Mais especificamente, a dualidade "expectativa de direito", como posições jurídicas mantidas ao longo do tempo, porém destituídas de qualquer tutela jurídica e "direito adquirido", como única condição que põe a salvo o direito que se formou integralmente, não dá conta de conferir segurança jurídica em tema de direitos sociais cujos requisitos de elegibilidade somente são alcançados após décadas de filiação ao sistema de proteção, como é o caso das aposentadorias voluntárias - aposentadoria por tempo de contribuição, destacadamente ${ }^{3}$.

Na terceira e última parte do texto, da perspectiva do respeito devido à segurança jurídica dos trabalhadores, analisa-se o tratamento transitório previsto na Proposta de Emenda Constitucional 006/2019 para a obtenção de aposentadoria por tempo de contribuição em ambos regimes públicos de previdência social. Para tanto, fez-se necessário, também, uma confrontação do conjunto normativo vigente com aquele contido na "Nova Previdência".

\section{SEGURANÇA JURÍDICA PELA PROTEÇÃO DOS DIREITOS ADQUIRIDOS}

A proteção constitucional da segurança jurídica pode ser compreendida fundamentalmente na vedação à retroatividade da lei, assim como nos institutos do direito adquirido, da coisa julgada e do ato jurídico perfeito.

3 De fato, "A relação jurídica previdenciária não se forma em um só tempo, momento ou ato, pois exige um longo e sucessivo trato de tempo de contribuição por parte do segurado contribuinte e de recebimento de benefício por parte do segurado beneficiário. Os direitos previdenciários são adquiridos em fragmentos, tempo a tempo, contribuição a contribuição. Por isso, tão importante quanto proteger os direitos previdenciários formados é proteger os direitos previdenciários em formação, pois deve existir também uma proteção sobre o tempo decorrido, que não volta mais. Exsurge daí a importância de se ocupar da fase potencial da relação jurídica previdenciária e da expectativa na formação dos direitos previdenciários e sua necessidade de proteção". CAMPOS, Marcelo Barroso Lima Brito de. Direitos previdenciários expectados: a segurança na relação jurídica previdenciária dos servidores públicos. Curitiba: Juruá, 2012, p. 259. 
Em regra, uma norma deve ser prospectiva e excepcionalmente pode ser retrospectiva (retroatividade mínima), mas, quando se tratar de norma restritiva de direitos, não deve ser integralmente retroativa, pelo fato de que o cidadão não pode se guiar, evitando ou praticando um ato, por uma norma que não existia na época do ato por ele praticado, não podendo prever sua conduta de acordo com norma que não existe.

Mas essa vedação à retroatividade não protege o indivíduo em relação a atos que ainda estão em formação ou em relação às expectativas que são geradas por atos deste mesmo Estado, que poderão ter que se submeter à edição de novas normas mais gravosas. Como proceder, então, quando atos jurídicos praticados sob a vigência da lei velha, que fazem parte de um encadeamento de eventos necessários para a constituição de um fato jurídico que implica direito subjetivo, produzirem efeitos apenas quando a lei nova já se encontrar em vigor - o que é, basicamente, a rotina do direito previdenciário ${ }^{4}$

Por outro lado, desde a Constituição de 1934 (art. 113, inc. 3), é previsto que "a lei não prejudicará o direito adquirido, o ato jurídico perfeito e a coisa julgada". As Constituições seguintes, com exceção da Constituição do Estado Novo (1937), também previram proteção semelhante. Atualmente, esses direitos e essas garantias encontram-se protegidos no art. $5^{\circ}, \mathrm{XXXVI}$, da Constituição Federal de 1988.

A finalidade de se promulgarem tais direitos fundamentais no texto constitucional também era proteger o cidadão de eventuais interpretações retroativas dos textos legais, pois a vedação à retroatividade das leis não bastava, em alguns casos em que a eficácia temporal da lei não estivesse clara.

4 Sobre a distinção entre retroatividade autêntica - em que as leis restritivas de direitos afetam posições jusfundamentais já estabelecidas no passado, ou mesmo esgotadas - da retroatividade inautêntica - em que a lei proclama a vigência para o futuro, mas afeta direitos ou posições radicadas na lei anterior, veja-se: CANOTILHO, José Joaquim Gomes; MOREIRA, Vital. Constituição da República Portuguesa Anotada. Volume I, $4^{\mathrm{a}} \mathrm{Ed}$. Coimbra: Coimbra Editora, 2007, p. 393-394. 
Em suma, segundo esses institutos, um novo ato estatal não pode produzir efeitos perante direitos já constituídos segundo a ordem jurídica anterior ${ }^{5}$. São importantes na seara dos direitos sociais as garantias de ato jurídico perfeito - a lei nova não pode desprezar a eficácia de um ato jurídico já consumado segundo a lei anterior por ela revogada - e da coisa julgada - que têm por objetivo evitar que uma nova decisão judicial afete a eficácia de uma decisão judicial anterior, sobre um mesmo processo, com as mesmas partes e o mesmo pedido, evitando-se a perenidade das discussões judiciais sobre o mesmo tema e entre as mesmas pessoas. Sem embargo, para fins do presente trabalho, mais relevante se torna a análise do direito adquirido.

Partindo da doutrina de Gabba, José Afonso da Silva trata com extrema didática as categorias jurídicas relacionadas ao direito adquirido, como expectativa de direito, direito subjetivo, direito exercitável e direito consumado 6 . Importa a distinção entre um direito consolidado, ainda que não exercitado, e um mero interesse legítimo, aqui englobando fatos pendentes, em curso, e fatos futuros.

$5 \quad$ A Lei de Introdução às Normas do Direito Brasileiro (Decreto-Lei 4.657, de 04 de novembro de 1942 ) no art. $6^{\circ}$, em sua versão original, previa que "A lei em vigor terá efeito imediato e geral. Não atingirá, entretanto, salvo disposição expressa em contrário, as situações jurídicas definitivamente constituídas e a execução do ato jurídico perfeito." Não se falava de 'direito adquirido'. Apenas com a modificação desse dispositivo, pela Lei 3.238/57, esse mesmo Decreto-Lei 4.657/42 assim conceituou ato jurídico perfeito, coisa julgada e direito adquirido: "Art. $6^{\circ} \mathrm{A}$ Lei em vigor terá efeito imediato e geral, respeitados o ato jurídico perfeito, o direito adquirido e a coisa julgada. $\S 1^{\circ}$ Reputa-se ato jurídico perfeito o já consumado segundo a lei vigente ao tempo em que se efetuou. $\S 2^{\circ}$ Consideram-se adquiridos assim os direitos que o seu titular, ou alguém por ele, possa exercer, como aqueles cujo começo do exercício tenha termo pré-fixo, ou condição pré-estabelecida inalterável, a arbítrio de outrem. $\S$ $3^{\circ}$ Chama-se coisa julgada ou caso julgado a decisão judicial de que já não caiba recurso."

6 “A doutrina ainda não fixou com precisão o conceito de 'direito adquirido'. É ainda a opinião de Gabba que orienta sua noção, destacando como seus elementos caracterizadores: (a) ter sido produzido por um fato idôneo para sua produção; (b) ter-se incorporado definitivamente ao patrimônio do titular. [...] Para compreendermos um pouco melhor o que seja o direito adquirido, cumpre relembrar o que se disse acima sobre o direito subjetivo: é um direito exercitável segundo a vontade do titular e exigível na via jurisdicional quando seu exercício é obstado pelo sujeito obrigado à prestação correspondente. Se tal direito é exercido, foi devidamente prestado, tornou-se situação jurídica consumada (direito consumado, direito satisfeito, extinguiu-se a relação jurídica que o fundamentava). [...] Se o direito subjetivo não foi exercido, vindo a lei nova, transforma-se em direito adquirido, porque era direito exercitável e exigível à vontade de seu titular. Incorporou-se ao seu patrimônio, para ser exercido quando lhe convier. A lei nova não pode prejudicá-lo só pelo fato de o titular não o ter exercido antes. 'Direito subjetivo' é a 'possibilidade de ser exercido, de maneira garantida, aquilo que as normas de Direito atribuem a alguém como próprio'. Ora, essa possibilidade de exercício continua no domínio da vontade do titular em face da lei nova. Essa possibilidade de exercício do direito subjetivo foi adquirido no regime da lei velha e persiste garantida em face da lei superveniente. Vale dizer - repetindo: o direito subjetivo vira direito adquirido quando lei nova vem alterar as bases normativas sob as quais foi constituído. Se não era direito subjetivo antes da lei nova, mas interesse jurídico simples, mera expectativa de direito ou, mesmo interesse legítimo, não se transforma em direito adquirido sob o regime da lei nova, que, por isso mesmo, corta tais situações jurídicas subjetivas no seu iter, porque sobre elas a lei nova tem aplicabilidade imediata, incide." SILVA, José Afonso da. Comentário contextual à Constituição. $3^{a}$ Ed. São Paulo: Malheiros, 2007, p. 133-134. 
Segundo a teoria predominante de Gabba, os interesses, ainda que legítimos, seriam meras expectativas, não podendo obter proteção do Poder Judiciário, de modo que a lei nova poderia surtir efeitos em relação a estes interesses legítimos, diferentemente do que ocorre com os direitos adquiridos.

O STF, na longínqua data de 25/06/1992, em julgamento que discutia a constitucionalidade do uso da TR - Taxa Referencial (índice de remuneração de valores pecuniários depositados em cadernetas de poupança) como índice de correção monetária de contratos de financiamento habitacionais anteriores à edição da Lei 8.176/91, adotou a teoria de Gabba, que subjaz à ideia de direito adquirido?

Desde então, não mais o STF reanalisou o conceito de direito adquirido, e a doutrina, interpretando essa decisão, passou a entender que o STF adotou a teoria de Gabba, de que não há retroatividade na lei nova de qualquer espécie, exceto em caso de lei penal mais benéfica ao réu

A essência da proteção ao direito adquirido em matéria previdenciária consiste na circunstância de que, uma vez cumpridos os requisitos para a obtenção de determinada prestação previdenciária, nenhuma circunstância superveniente, seja de fato, seja de direito, poderá afetar esse direito, mesmo que ele ainda não tenha sido exercido?.

$7 \quad$ ADI 493, Rel. Min. Moreira Alves, Tribunal Pleno, j. 25.06.1992, DJ 04.09.1992.

8 Atítulo ilustrativo, quando do julgamento da ADI 3104/DF (Rel. Min. Carmen Lucia, j. em 26.09.2007, DJ 09.11.2007), o STF deixou de reconhecer o direito dos servidores públicos filiados a Regime Próprio de Previdência Social às regras transitórias estabelecidas pela EC 20/98 e que haviam sido mutiladas pela EC 41/03. Embora se imputasse à alteração normativa a inconstitucionalidade por afronta a princípios como segurança jurídica, proteção da confiança do cidadão e boa-fé administrativa, e a questão foi solucionada na perspectiva da inexistência de direito adquirido a regime jurídico.

9 Nesse sentido: "Ressalvada a revisão prevista em lei, os proventos da inatividade regulam-se pela lei vigente ao tempo em que o militar, ou o servidor civil, reuniu os requisitos necessários" (STF, Súmula 359). E mais especificamente: "Aposentadoria: proventos: direito adquirido aos proventos conformes à lei regente ao tempo da reunião dos requisitos da inatividade, ainda quando só requerida após a lei menos favorável (Súmula 359, revista): aplicabilidade a fortiori, à aposentadoria previdenciária. (RE 258.298-1/RS, Rel. Min. Sepúlveda Pertence, $1^{\text {a }}$ Turma, j. 14.12.1999, DJ 17.03.2000). Importa notar que a redação originária da Súmula 359 exigia, para reconhecer o direito como adquirido, não apenas a reunião dos requisitos, mas igualmente o seu exercício. 


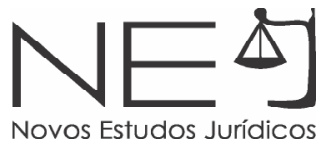

Só que a tese de Gabba é omissa e incompleta, quando se está diante de relações em formação, de expectativas que vão se formando e se solidificando no tempo. As críticas à teoria do direito adquirido de Gabba confirmam as assertivas, e até hoje não foram bem respondidas por seus defensores ${ }^{10}$.

Além disso, a teoria do direito adquirido de Gabba, elaborada há quase dois séculos, prevalecente no STF, precisa ser reavaliada em meio a dois fatos sociais modernos, que pugnam pela evolução do entendimento manifestado na ADI 493: a) a isonomia exigida pela massificação das relações entre o Estado e a população (evoluindo numericamente a passos largos), com a caracterização do Estado como litigante habitual (Estado-Juiz), como solicitado e distribuidor de direitos habitual (Estado-Administrador) e como instituidor e desinstituidor habitual de direitos (Estado-Legislador); e b) a preponderância bastante significativa dos facta pendentia (fatos realizados em regimes legais anteriores, mas com efeitos ainda não consumados) em face dos facta praeterita (fatos realizados e com efeitos consumados em regimes legais anteriores), especialmente diante da aceleração na produção e na alteração de normas, demandando proteção de expectativas nas relações entre Estado e particulares (diferentemente das relações estritamente privadas que presidiam o estudo e a prática do Direito na época de Gabba e da prolação da decisão da ADI 493).

\section{A NECESSÁRIA TUTELA JURÍDICA DOS DIREITOS EM FORMAÇÃO}

O tema das garantias dos direitos dos beneficiários da Segurança Social constitui uma questão central, de importância crucial nos debates em curso sobre o futuro da proteção dos riscos sociais e o modo de fazer diante das suas dificuldades. ${ }^{11}$ Tal referência ganha realce quando "parece, de facto, pouco discutível que os modernos sistemas de segurança social europeus estão, de um modo geral, demasiadamente politizados, no sentido que as práticas políticas e os interesses políticos, muitas vezes conjunturais, levaram pouco a crer que na

10 Dentre as críticas sofridas por essa doutrina, como aponta Vicente Ráo, encontra-se a que se fundamenta no argumento de que a "definição de Gabba, aludindo à ocasião em que o direito adquirido é feito valer, como sendo aquela em que impera uma lei nova e diversa, parece excluir os direitos que se exercem por atos continuados, ou sucessivos, que tanto se verificam sob a lei antiga, quanto sob a lei nova". RÁO, Vicente. O direito e a vida dos


p. 373.

11 NEVES, Ilídio das. Crise e Reforma da Segurança Social, Coimbra: Coimbra Editora, 1996, p. 180. 
segurança social tudo é passível de decisão, de modificação", de maneira que "a segurança social tornou-se um verdadeiro laboratório de sucessivas experiências". A política teria se apropriado dos sistemas de segurança social, "o que deu origem a distorções e incoerências, quantas vezes com facturas financeiras meramente implícitas, escondidas, para se revelarem no futuro". ${ }^{12}$

No Brasil a doutrina do direito intertemporal consagrou a regra do efeito imediato sobre as situações jurídicas em curso de constituição, situações essas que, consoante expressa Cláudia Toledo, "porque ainda não totalmente constituídas, apresentam-se como meras expectativas de direito". Mas dependendo da relevância social que assumem, acrescenta a mesma doutrinadora, "para a manutenção da estabilidade social advinda da confiança dos indivíduos no ordenamento jurídico, deve o legislador estabelecer normas de transição, como aquelas existentes na Emenda Constitucional n. 20 de 1998 à Constituição Federal de 1988".13

Como articulado na seção anterior, o Supremo Tribunal Federal apenas tem considerado o direito adquirido (e não os direitos em formação) como formulação de segurança jurídica. Na observação de José Adércio Leite Sampaio ${ }^{14}$,

(...) tem-se entendido que até o instante em que o trabalhador não reunir todos os requisitos exigidos para aposentação, ele goza apenas de mera 'expectativa de direito'. Que falte um mês para completar seu tempo de serviço ou de contribuição, viverá de esperança, não de proventos. Há incidência imediata de nova disciplina previdenciária, sem capacidade para retroagir no tempo, mas capaz de impedir uma aposentadoria que, antes, seria em breve. Agora, um talvez indefinido.

Com efeito, a jurisprudência brasileira, sem cuidar expressamente de medidas de proteção de cunho subjetivo, caminhou para a consolidação do entendimento de que não existe direito adquirido a regime jurídico.

12 NEVES, Ilídio das. Crise e Reforma da Segurança Social. p. 131.

13 TOLEDO, Cláudia. Direito Adquirido e Estado Democrático de Direito, Belo Horizonte: Landy Editora, 2003, p. 192193.

14 SAMPAIO, José Adércio Leite. Expectativa de Direito e Direito Adquirido como Franquias e Bloqueios da Transformação Social. In ROCHA, Carmen Lúcia Antunes (Org.). Constituição e segurança jurídica: direito adquirido, ato jurídico perfeito e coisa julgada. Estudos em homenagem a José Paulo Sepúlveda Pertence. $2^{\mathrm{a}}$ edição, Belo Horizonte: Fórum, 2005, p. 314. 
A ideia é antiga e tem como representante a letra do Ministro Moreira Alves, que no RE 94.020, em 04/11/1981, assim decidiu:

(...) em matéria de direito adquirido vigora o princípio - que este Tribunal tem assentado inúmeras vezes - de que não há direito adquirido a regime jurídico de um instituto de direito. Quer isso dizer que, se a lei nova modificar o regime jurídico de determinado instituto de direito (como é o direito de propriedade, seja ela de coisa móvel ou imóvel, ou de marca), essa modificação se aplica de imediato.

Parece que essa ideia, embasada no direito adquirido, comporta atualização, por se mostrar insuficientes à proteção da segurança jurídica do cidadão e à concreta legitimidade do próprio Estado, especialmente quando o ato em questão ainda se encontrar em formação. A modernidade, portanto, vem cobrando uma fundamentação mais adequada dos atos estatais de todos os poderes, o que ainda não é uma realidade no Estado brasileiro, em detrimento da segurança jurídica dos indivíduos. Neste sentido:

A proteção da confiança e o direito adquirido são conceitos que não se igualam. Este último protege posições jurídicas integral e definitivamente incorporadas ao patrimônio de um particular, algo que já foi integralizado em um momento anterior ao de uma dada alteração normativa. Serve para essencialmente proteger relações jurídicas concluídas no passado. Já a proteção da confiança vai além, e pode garantir posições jurídicas ainda não encerradas ou, até mesmo, nascidas de atos estatais ilegais. Isso faz com que a doutrina alemã enxergue, inclusive, o princípio da proteção da confiança como algo mais amplo, como um gênero (Obergbegriff), do qual o instituto do direito adquirido seria parte (Teilbegrif). $O$ respeito à continuidade das normas e do ordenamento não deve ser apenas garantido através da proteção dos direitos adquiridos. Essa continuidade pressupõe um alcance maior, ao também exigir do Estado uma consistência na mudança (Beständigkeit im Wandel) e na tutela de expectativas legitimas. ${ }^{15}$

O ponto fundamental a se reconhecer, portanto, é o de que a alteração no quadro normativo dos direitos sociais de seguridade social deverá guardar respeito à segurança jurídica, aos cálculos operados pelos indivíduos, à confiança que emprestou às regras do jogo então estabelecidas, pois não é aceitável que

15 ARAÚJO, Valter Shuenquener de. O princípio da proteção da confiança: uma nova forma de tutela do cidadão diante do Estado. $2^{\text {a }}$ Ed. Niterói: Impetus, 2016, p. 79-80. 
simplesmente se desprezem o planejamento da vida e os comportamentos pautados por ele, manifestados em longo tempo de filiação e contribuiç̧ão para os sistemas previdenciários. Como consequência, no caso de alteração normativa mais gravosa (estabelecimento de novos requisitos de elegibilidade, v.g.), torna-se necessário o reconhecimento do direito a uma transição razoável para o trabalhador que já se encontrava filiado ao sistema previdenciário quando do advento da nova lei ${ }^{16}$.

De acordo com o ensino de Ingo Sarlet, a partir do pensamento de Martin Wolff, desenvolveu-se o "ponto de vista de que o conceito de propriedade abrange toda sorte de direitos subjetivos privados de natureza patrimonial, o que acabou por levar à afirmação de um conceito funcionalista de propriedade". A garantia da propriedade, assim concebida, não protegeria apenas a propriedade no âmbito dos direitos reais, mas alcançaria uma "função conservadora de direitos, no sentido de que ela igualmente tem por escopo oferecer ao indivíduo segurança jurídica relativamente aos direitos patrimoniais reconhecidos pela ordem jurídica, além de proteger a confiança depositada no conteúdo de seus direitos". ${ }^{17}$

Acolhendo esse entendimento doutrinário, o Tribunal Federal Constitucional tem reconhecido que as posições jurídicas que conduzem os sujeitos a um bem de natureza pública (posiçõesjurídico-subjetivas patrimoniais de natureza pública) devem ser protegidas pela garantia fundamental da propriedade por merecerem, em um Estado de Direito, tratamento igualitário relativamente às posições jurídico-subjetivas privadas ${ }^{18}$. O reconhecimento dessa proteção tem seu principal fundamento "na estreita vinculação entre

16 Como expressa Luís Roberto Barroso: "A expectativa de direito identifica a situação em que o ciclo de eventos previstos para a aquisição do direito já foi iniciado, mas ainda não se completou no momento em que sobrevém uma nova norma alterando o tratamento jurídico da matéria. Nesse caso, não se produz o efeito previsto na norma anterior, pois seu fato gerador não se aperfeiçoou. Entende-se, sem maior discrepância, que a proteção constitucional não alcança essa hipótese, embora outros princípios, no desenvolvimento doutrinário mais recente (como o da boa-fé e o da confiança legítima), venham oferecendo algum tipo de proteção também ao titular da expectativa de direito. É possível cogitar, nessa ordem de ideias, de direito a uma transição razoável." BARROSO, Luís Roberto. Curso de Direito Constitucional Contemporâneo. $7^{\text {a }}$ Ed. São Paulo: Saraiva Educação, 2018, p. 222223.

17 SARLET, Ingo Wolfgang. O Estado Social de Direito, a Proibição de Retrocesso e a Garantia Fundamental da Propriedade. Revista Diálogo Jurídico, Salvador, CAJ - Centro de Atualização Jurídica, v. I, nº. 4, julho, 2001. Disponível em: <http://www.direitopublico.com.br>. Acesso em: 20 de fevereiro de 2006.

18 STAFFEN, Marcio Ricardo; ARSHAKYAN, Mher. The legal development of the notion of human dignity in the constitutional jurisprudence. Revista Brasileira de Direito, Passo Fundo, v. 12, n. 2, p. 108-126, dez. 2016. 


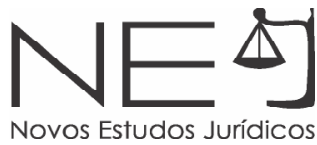

o direito de propriedade e a liberdade pessoal, no sentido de que ao indivíduo deve ser assegurado um espaço de liberdade na esfera patrimonial, de tal sorte que possa formatar de maneira autônoma sua existência". Mais do que isso, ao titular de uma posição jurídico-subjetiva de natureza pública é atribuída uma posição jurídica equivalente à da propriedade privada, sendo vedada pelo princípio do Estado de Direito uma supressão sem qualquer compensação. Com efeito, deve ser reconhecida como paradigmática a virtual equiparação do titular das posições subjetivas de direito público com a condição do proprietário. ${ }^{19}$

Assim é que, especialmente em relação às prestações diferidas no tempo (direitos de formação complexa, como os de aposentadorias voluntárias), as expectativas de direito, ou melhor, as posições jurídicas conquistadas pelo segurado que tendam a lhe atribuir determinado direito prestacional, se transformam nos chamados direitos em formação, que se distinguem dos direitos adquiridos porque o beneficiário não completou todos os requisitos legalmente exigíveis, mas que, sem embargo, devem gozar de determinado nível de garantia (proteção jurídica).

Essas reflexões ressaltam que a razão ou justificativa para a proteção das posições jurídicas individuais em face do direito à uma prestação da Seguridade Social não pode pautar-se por uma lógica do tudo (direitos adquiridos) ou nada (direitos em formação), tal como insiste em expressar a jurisprudência do Supremo Tribunal Federal.

A tutela jurídica dos direitos em formação revela-se de destacada importância quando se tem em conta que o processo de aquisição do direito a determinadas prestações, pela sua própria natureza, se prolonga no tempo, atravessando gerações, trilhando décadas e transitando por diferentes cenários ideológicos e socioeconômicos.

19 SARLET, Ingo Wolfgang. O Estado Social de Direito, a Proibição de Retrocesso e a Garantia Fundamental da Propriedade. p. 8. 
A garantia dos direitos em formação decorre do direito de segurança do indivíduo quanto aos efeitosjurídicos de seus próprios atose, mais especificamente, da proteção da confiança ${ }^{20}$, da expectativa, ou da presunção decorrente do ordenamento jurídico no sentido de que o segurado se beneficiará da aplicação de determinada legislação que the garante o benefício em condições nunca inferiores às que constituíam o objeto da relação jurídica de segurança social no momento da vinculação. ${ }^{21}$

\section{Como vaticina llídio das Neves, uma vez que o direito à Segurança Social} não é ou não deve ser considerado uma dádiva mais ou menos arbitrária do Estado, "um simples produto ad hoc do poder legislativo conjunturalmente actuante, mas antes o reconhecimento pelo Estado de determinados valores, como são os princípios de justiça distributiva e da segurança jurídica, bem como da regra da boa-fé na produção e na aplicação do direito", encontrase a justificação para a garantia dos direitos em formação ${ }^{22}$. O autor invoca a teoria dos fatos passados como fundamento para que se defina um quadro preciso dos efeitos jurídicos a atribuir a fatos fundamentais na relação jurídica de segurança social, como a inscrição no sistema, o enquadramento em um regime, a ocorrência de uma eventualidade ou a verificação de um fato relevante como condição essencial do reconhecimento do direito a prestações (tempo de contribuição, idade, etc). ${ }^{23}$

20 Como anota Ingo Sarlet, o princípio da proteção da confiança é um dos elementos materiais do princípio da boafé, "tendo por corolário - notadamente no âmbito das relações negociais - o dever da parte de não fraudar as legítimas expectativas criadas pelos próprios atos, o que evidencia a conexão direta da boa-fé com a proteção da confiança no sentido de uma certa auto-vinculação dos atos e, portanto, de uma inequívoca relação com a noção de proibição de retrocesso". SARLET, Ingo Wolfgang. A eficácia do direito fundamental à Segurança Jurídica: dignidade da pessoa humana, direitos fundamentais e proibição de retrocesso social no direito constitucional brasileiro. In ROCHA, Carmen Lúcia Antunes (Org.). Constituição e segurança jurídica: direito adquirido, ato jurídico perfeito e coisa julgada. Estudos em homenagem a José Paulo Sepúlveda Pertence. $2^{\mathrm{a}}$ edição, Belo Horizonte: Fórum, 2005, p. 97-98.

21 NEVES, llídio das. Crise e Reforma da Segurança Social. Equívocos e Realidades. p. 168.

22 Sobre tema tão caro, importa transcrever a bem-posta ponderação do autor: "A relação jurídica da segurança social constituída entre o cidadão e o sistema, embora não tenha, naturalmente, uma base contratual, nem por isso pode deixar de implicar um compromisso jurídico mútuo minimamente consistente e estável, incompatível com uma simples promessa ad nutum por parte do Estado, sujeita ao arbítrio dos imponderáveis das mudanças legislativas e das alterações imprevisíveis do poder político. Se assim não fosse, em vez de uma obrigação clara do Estado, que ficaria vinculado a cumpri-la, teríamos uma espécie de direito potestativo deste. Neste caso os beneficiários não poderiam opor-se a qualquer alteração radical que eventualmente ocorresse no conteúdo do seu direito à segurança social. Em tal situação, do lado do beneficiário, em lugar de um direito, haveria um simples estado de sujeição, ou seja, uma aparência de direito, que existiria e valeria unicamente se e enquanto o poder político quisesse. A protecção pela segurança social estaria inteiramente sujeita a um estatuto de condicionalidade, precariedade e provisoriedade, incompatível com a sua natureza jurídica e social e com os objectivos de justiça social que lhe servem de suporte político-social. Seria uma inversão total das posições jurídicas" NEVES, llídio das. Crise e Reforma da Segurança Social. Equívocos e Realidades. p. 169.

23 NEVES, llídio das. Crise e Reforma da Segurança Social. Equívocos e Realidades. p. 175. 
Ao ver do mesmo tratadista português, somente com a proteção dos direitos em formação é que "será possível reconstituir a confiança, em geral perdida, enfraquecida ou, pelo menos, bastante abalada, entre os cidadãos e o Estado no âmbito do sistema público de segurança social". E acrescenta: "Não é pelo facto de se falar pouco deste elo de confiança que deve existir, no mais elevado grau possível, entre o sistema e as pessoas por ele abrangidas que a questão é suscetível de ser subestimada. Ora, sem um nível muito forte de confiança nenhum sistema conseguirá a eficácia adequada à correcta avaliação das necessidades de protecção dos cidadãos e à justa afectação dos recursos disponíveis ou que se pensa poderem ser disponibilizados. Mas sem segurança jurídica não é possível consolidar a confiança dos cidadãos". 24

A falta de confiança nos sistemas previdenciários é, sem dúvida, um dos fatores concorrentes para a evasão de cotizações, tido este como um problema capital na concepção e no funcionamento dos programas contributivos de prestações da seguridade social. ${ }^{25}$ Como escreve Ingo Sarlet, anteriormente mencionado, o reconhecimento de um determinado grau de proteção às expectativas de direitos leva à necessidade de se estabelecer regras de transição razoáveis, nos casos de alteração de determinados regimes jurídicos, conforme reiterada jurisprudência do Tribunal Federal Constitucional da Alemanha. ${ }^{26}$

Nessa mesma direção fala Marcelo Barroso $\operatorname{Campos}^{27}$ dos direitos expectados:

O suceder de fatos da vida, que ocorrem ao longo do tempo, formam no seu conjunto, um plexo que, ao cabo, se denomina direito adquirido, esse o ponto de chegada, a expectativa de direito é, pois, a caminhada. Esses fatos sucessivos no tempo, isoladamente, não constituem direitos adquiridos, mas o seu conjunto, a sua unidade, configura um

24 NEVES, llídio das. Crise e Reforma da Segurança Social. Equívocos e Realidades. p. 180.

25 GILLION, Colin et al. Pensiones de Seguridad Social, Desarrollo y reforma, Informes OIT, n. 57, Madrid: Ministerio de Trabajo y Asuntos Sociales, 2002, p. 384.

26 Também merece referência a anotação do eminente mestre gaúcho, fundada na experiência do Tribunal Federal Constitucional da Alemanha, de que uma graduação da proteção da confiança do segurado segundo o tempo pelo qual foram preservadas suas posições jurídicas: "tanto maior deverá ser a garantia da segurança jurídica individual, quanto mais merecedora de proteção for a confiança depositada pelo indivíduo no sistema vigente, proteção esta vinculada também ao fato tempo". Em outras palavras, as medidas de transição legislativa dão lugar a tratamento diferenciado conforme o momento em que se encontrava o indivíduo em relação ao cumprimento dos pressupostos para a obtenção do benefício. SARLET, Ingo Wolfgang. A eficácia do direito fundamental à Segurança Jurídica: dignidade da pessoa humana, direitos fundamentais e proibição de retrocesso social no direito constitucional brasileiro. In ROCHA, Carmen Lúcia Antunes (Org.). Constituição e segurança jurídica: direito adquirido, ato jurídico perfeito e coisa julgada. Estudos em homenagem a José Paulo Sepúlveda Pertence. p. 97 e $125-126$.

27 CAMPOS, Marcelo Barroso Lima Brito de. Direitos previdenciários expectados: a segurança na relação jurídica previdenciária dos servidores públicos. p. 259. 
direito. Logo, os direitos que não nascem instantaneamente, para serem adquiridos um dia, dependem dos seus fatos antecessores constituintes, isto é, depende das expectativas sobre as quais se fundam, sem as quais nunca chegariam a ser direitos adquiridos. Em consequência, a proteção aos direitos expectados e das expectativas de direitos é tão importante.

Em suma, as possíveis mudanças estatais, além do devido respeito a direitos adquiridos, atos jurídicos perfeitos e coisa julgada atinente às decisões jurisdicionais transitadas em julgado, tendo em vista se tratarem de situações mais que consolidadas pelo tempo, também não podem desrespeitar o que está a vir, o que está em formação: as expectativas legítimas dos cidadãos geradas pelo próprio Estado.

Cumpre, agora, analisar o direito transitório que se pretende oferecer por meio da PEC 006/2019, que consiste na Nova Reforma Previdenciária - ou a "Nova Previdência", como orgulhosamente foi apresentada por seus arautos.

\section{DIREITO TRANSITÓRIO NA CHAMADA “NOVA PREVIDÊNCIA”}

No dia 07/08/2019, o relatório do deputado Samuel Moreira (PSDB-SP), sobre a PEC 6/2019 (Nova Previdência ${ }^{28}$ ), foi aprovado em segundo turno na Câmara dos Deputados. Atualmente, encontra-se em discussão legislativa no Senado Federal.

Importa para o presente trabalho a avaliação do respeito à segurança jurídica em relação à aposentadoria por tempo de contribuição, mediante garantia de direito transitório adequado. Veja-se, pois, em que medida os direitos em formação foram respeitados, tanto no Regime Geral da Previdência Social (RGPS) como no Regime Próprio de Previdência Social (RPPS).

28 A expressão "Nova Previdência", empregada por integrantes do Governo Bolsonaro já com as primeiras referências à Proposta de Emenda Constitucional 006/2019, que visa à modificação do sistema de previdência social, bem traduz o elevado impacto das mudanças que buscava impor, podendo-se citar, como exemplo, a idealização até mesmo de um regime de capitalização, ao lugar do tradicional regime de repartição. A expressão "Nova Previdência" deixa notar a pretensão de não apenas se ajustar alguns parâmetros do sistema previdenciário, mas de se empreender uma verdadeira alteração de paradigma em termos de proteção social, tendo como princípio motivador o equilíbrio financeiro e atuarial do orçamento da seguridade social, entendido em uma dimensão de eficiência econômica e imediata redução de gastos públicos. 


\subsection{PROPOSTAS DE ALTERAÇÕES PARA O REGIME GERAL DA PREVIDÊNCIA SOCIAL (RGPS)}

É difícil compreender a manutenção da aposentadoria por tempo de contribuição na forma simplória que atualmente se tem, por meio da qual se concede aposentadoria apenas com base em um determinado tempo de contribuição, sob uma análise muito simples: que risco social é protegido ao se conceder uma aposentadoria a um cidadão com algo em torno dos 50 anos de idade, com saúde plena e que ainda vai continuar trabalhando? Não há risco social atrelado à aposentadoria por tempo de contribuição, diferentemente de todas as outras espécies de benefícios e aposentadorias da Previdência Social ${ }^{29}$. Portanto, esta fixação de uma idade mínima, para aposentadorias regulares e programáveis, seria uma das medidas que se poderia pensar como legítima em uma reforma da Previdência adequada.

Isto não justifica, entretanto, a ausência de uma regra de transição justa e equilibrada para aqueles que iniciaram sua vida laborativa anteriormente às mudanças previstas.

Atualmente, a PEC 006/2019 projeta a alteração do inciso I do art. 201 da CF nos seguintes termos:

Art. 201. A previdência social será organizada sob a forma do Regime Geral de Previdência Social, de caráter contributivo e de filiação obrigatória, observados critérios que preservem o equilíbrio financeiro e atuarial, e atenderá, na forma da lei, a: I - cobertura dos eventos de incapacidade temporária ou permanente para o trabalho e idade avançada;

Nota-se, com isso, a consagração da ideia de que o risco social a ser protegido com a aposentadoria é a idade avançada.

29 Cabe notar, entretanto, a dificuldade encontrada pelas pessoas com idade próxima às exigidas para a concessão de aposentadoria por idade para entrarem ou permanecerem no mercado formal de trabalho. 
Atualmente, em suma, o cidadão, trabalhador urbano se aposenta por idade com 65/60 anos de idade mínima e 180 contribuições (15 anos) de carência. Essa aposentadoria é residual, para quando o cidadão não tem o tempo de contribuição necessário à concessão de uma aposentadoria por tempo de contribuição, que é de 35 anos para os homens e 30 anos para as mulheres ${ }^{30}$.

Essa formatação das aposentadorias muda sensivelmente com o texto da PEC 6/2019. Nesse viés, a Câmara dos Deputados definiu que nenhum trabalhador, excetuada a pessoa com deficiência, deveria se aposentar antes dos 55 anos de idade, por se compreender que antes da referida idade haveria capacidade para manter a atividade produtiva e que não seria razoável sobrecarregar as novas gerações com aposentadorias concedidas antes dessa idade mínima ${ }^{31}$. Em relação aos trabalhadores urbanos em geral, extingue-se a aposentadoria por tempo de contribuição e garante-se a aposentadoria por idade, que teve a idade mínima fixada em 65 anos, se homem, e de 62 anos, se mulher, com 15 anos de contribuição mínima ${ }^{32}$.

Assim, nota-se que o desiderato da PEC é manter a ideia de instituição apenas de uma aposentadoria por idade, aos 65/62 anos (homens/mulheres), com carência/contribuição mínima de 20/15 anos (homens/mulheres), para os trabalhadores urbanos ${ }^{33}$.

30 Ainda, o trabalhador pode se aposentar com alguma incapacidade laboral permanente ou com uma contagem de tempo qualificada, caso seja pessoa com deficiência ou trabalhe em condições especiais que prejudiquem sua saúde ou sua integridade física. Não há idade mínima para a aposentadoria por tempo de contribuição, nem para a aposentadoria especial, para a qual se exige ao menos 25 anos de atividades prestadas sob condições especiais que prejudiquem a saúde ou a integridade física. Para os trabalhadores rurais, permite-se, atualmente, a concessão de aposentadoria por idade com 60/55 anos e uma redução do tempo de contribuição em 5 anos para a aposentadoria por tempo de contribuição desses trabalhadores.

31 Caso, no entanto, seja constatado que faltariam condições laborativas, o segurado continuaria tendo acesso à aposentadoria por incapacidade permanente, sem limite etário.

32 Quanto aos professores de educação infantil, fundamental e média, que antes se aposentavam com 30/25 anos de contribuição, sem idade mínima, foram propostas as idades mínimas de 60/57 anos (homens/mulheres).

33 A mesma lógica é proposta para os segurados empregados que sejam professores e que agora se aposentarão com 60/57 anos de idade mínima (homens/mulheres). No $\S 1^{\circ}$ do art. 201 da CF, notam-se ainda as aposentadorias diferenciadas, quais sejam, a da pessoa com deficiência e a de trabalhadores que exercem atividades prejudiciais à saúde, as quais escapam do objeto do presente estudo. 




3.2. REGRAS DE TRANSIÇÃO PREVISTAS PARA O REGIME GERAL DA PREVIDÊNCIA SOCIAL (RGPS)

A PEC 006/2019 foi aprovada na Câmara dos Deputados com cinco regras de transição, para as aposentadorias regulares, sem consideração de tempos especiais: (i) regime 96/86 (art. 15), (ii) tempo de contribuição + idade mínima progressiva (art. 16), (iii) tempo de contribuição + pedágio de $50 \%$ do tempo que faltar na data da EC (art. 17), (iv) idade + tempo de contribuição de 15 anos (art. 18) e (v) tempo de contribuição + idade mínima fixa + pedágio de 100\% (art. 20) (34 $^{34}$

Na primeira regra (regime 96/86: art. 15), os homens têm que cumprir, no mínimo, 35 anos de contribuição e as mulheres, 30 anos. Além disso, a soma da idade com o tempo de contribuição tem que resultar em 86 pontos para as mulheres e 96 pontos para os homens. Essa pontuação aumenta em um ponto, a cada ano, até atingir o limite de 105/100, H/M. Professores e professoras precisarão comprovar 30/25 anos e 91/81 pontos (até o limite de 100/92 pontos, H/M). O cálculo da RMI do benefício será de $60 \%$ do valor correspondente à média de todo o período contributivo, acrescido de $2 \%$ a cada ano de contribuição superior ao mínimo exigido.

Na segunda regra (tempo de contribuição + idade mínima progressiva: art. 16), exige-se que homens tenham 35 anos de contribuição e 61 anos de idade, e mulheres, 30 anos de contribuição e 56 anos de idade. A partir de $1^{\circ}$ de janeiro de 2020, as idades mínimas serão acrescidas de seis meses a cada ano, até atingir 62 anos de idade, se mulher, e 65 anos de idade, se homem. Professores e professoras precisarão comprovar 30/25 anos e 56/51 anos de idade, que também aumentarão paulatinamente. O cálculo da RMI do benefício será de $60 \%$ do valor correspondente à média de todo o período contributivo, acrescido de $2 \%$ a cada ano de contribuição superior ao mínimo exigido.

34 Também houve alteração na forma de cálculo das aposentadorias. O art. 26 da PEC 006/2019 estabelece fórmula mais gravosa e não há qualquer transição para o regime novo da forma de cálculo da RMI da aposentadoria, o que desrespeita a segurança jurídica e o Estado de Direito. Poderia ter sido prevista regra de transição adequada e suavizada, que permitisse ao segurado escolher entre a aplicação da nova norma ou a aplicação de uma regra de transição que considerasse ao menos um percentual do cálculo na forma antiga, conforme o momento em que o cidadão implementasse os requisitos para a concessão do benefício (não é relevante a data do requerimento) nos anos seguintes à mudança que eventualmente venha a ser feita pela EC. 
Pela terceira regra (tempo de contribuição + pedágio de $50 \%$ do tempo que faltar na data da EC: art. 17), os segurados que na data da promulgação da Emenda Constitucional contarem com 28 anos de contribuição, se mulher, e 33 anos de contribuição, se homem, poderão se aposentar quando cumprirem os seguintes requisitos cumulativos: (i) Mulher: 30 anos de contribuição $+50 \%$ do tempo que, na data de entrada em vigor da Emenda Constitucional, faltaria para atingir 30 anos de contribuição; (ii) Homem: 35 anos de contribuição + $50 \%$ do tempo que, na data de entrada em vigor da Emenda Constitucional, faltaria para atingir 35 anos de contribuição. Nesse caso, aplicável, portanto, a quem estiver a menos de dois anos de sua aposentadoria por tempo de contribuição, diferentemente, o cálculo da RMI será apurado de acordo com a média correspondente a todo o período contributivo desde a competência julho de 1994 ou desde o início da contribuição, se posterior àquela competência, multiplicada pelo fator previdenciário, calculado na forma do disposto nos $\S \S 7^{\circ}$ a $9^{\circ}$ do art. 29 da Lei n 8.213, de 24 de julho de 1991.

Entende-se, entretanto, que não consta qualquer justificativa para a exclusão daqueles que tivessem menos que 33/28 anos $(\mathrm{h} / \mathrm{m})$ de contribuição. Ora, parece muito mais razoável e proporcional que não houvesse esse corte abrupto, sem se permitir o acesso à norma de transição pelo pedágio a quem tivesse pouco menos que esse tempo de contribuição. O mais correto seria não haver limitação de acesso ao direito transicional pelo tempo de contribuição, pois a própria exigência do pedágio tornaria a regra de transição desinteressante àqueles que tivessem pouco tempo de contribuição e ainda estivessem longe da aposentadoria. Assim, o proponente atuou da mesma forma que foi conduzida inicialmente a PEC 287/2016, que em sua redação original previa um corte etário de 50/45 anos (h/m), negando o acesso à segurança jurídica a quem tivesse idade menor, independentemente de seu tempo de contribuição.

Pela quarta regra (idade + tempo de contribuição de 15 anos para ambos os sexos: art. 18), bastaria que se respeitassem os requisitos atuais para a concessão da aposentadoria por idade do trabalhador urbano: 65/60 anos de idade e 15 anos de contribuições. Há a previsão do aumento da idade mínima da mulher 


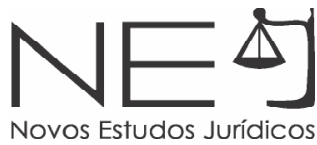

em seis meses a cada ano, até os 62 anos, iniciando-se em 01/01/2020. Para esses beneficiários, o cálculo da RMI da aposentadoria será de $60 \%$ do valor correspondente à média de todo o período contributivo, acrescido de $2 \%$ a cada ano de contribuição superior ao mínimo exigido.

Por fim, pela quinta regra de transição (tempo de contribuição + idade mínima fixa + pedágio de 100\%: art. 20), exige-se que homens tenham 35 anos de contribuição e 60 anos de idade, e mulheres 30 anos de contribuição e 57 anos de idade. Não haverá aumento dessa idade mínima; todavia, para se aposentar, o trabalhador terá que trabalhar por um período adicional de contribuição (pedágio) correspondente ao tempo que, na data de entrada em vigor da Emenda Constitucional, faltaria para atingir 35/30 anos de contribuição. Professores e professoras precisarão comprovar 30/25 anos e 55/52 anos de idade. O cálculo da RMI do benefício será de $60 \%$ do valor correspondente à média de todo o período contributivo, acrescido de $2 \%$ a cada ano de contribuição superior ao mínimo exigido.

\subsection{OS REGIMES PRÓPRIOS DE PREVIDÊNCIA SOCIAL E A SEGURANÇA} JURÍDICA

Pelo texto da PEC 6/2019, a idade mínima dos servidores passa imediatamente a 61/56 anos de idade, aumentando em relação aos 60/55 anos (homem/mulher) até então exigidos. Em 2022, a idade mínima passa a ser de $62 / 57$ anos (homem/mulher). Além disso, passa-se a exigir o somatório da idade e do tempo de contribuição, incluídas as frações, equivalente a 96/86 pontos (homem/mulher). O número mínimo de pontos será elevado, a partir de janeiro de 2020, até o limite de 100 pontos para mulher e 105 pontos para o homem, e poderá sofrer alterações a depender do aumento da expectativa de sobrevida. Essa já era a ideia original da PEC, mantida pelo relator. O art. 46, II da PEC 6/19, em sua versão original, trazia a possibilidade de revogação de normas transitórias de Emendas Constitucionais anteriores (EC's 20, 41 e 47), elaboradas como parte de anteriores reformas previdenciárias. O relator 
Novos Estudos Jurídicos

manteve essa revogação pretendida, ipsis litteris, ao editar o art. 37, II, III e IV, da PEC. As normas constitucionais cujas revogações são pretendidas tratam de regras de transição determinadas nas referidas reformas previdenciárias, para servidores públicos civis, de acordo com suas datas de ingresso no serviço público, se anteriores às respectivas datas de promulgação das Emendas.

Tanto a Emenda 20/98 (art. $3^{\circ}$ ) como a Emenda 41/2003 (art. $3^{\circ}$ ) asseguram o direito adquirido à pensão e à aposentadoria aos servidores que preencheram os requisitos até a data de suas publicações. Note-se que não tem qualquer relevância a data do requerimento administrativo do benefício, para aferição de qual regra se utilizar - o que importa é a data em que o cidadão preenche os requisitos, tempus regit actum.

Anteriormente à citada EC 20/98, ao servidor bastava o tempo de serviço (35 anos para o homem e 30 anos para a mulher) para a concessão de sua aposentadoria, com proventos integrais. Não era exigida idade mínima.

Havia uma regra de transição no art. $8^{\circ}$ da EC 20/98 para os servidores que ingressaram antes dessa emenda, que previa a concessão de aposentadoria, de modo integral (com base em sua última remuneração), e pela qual o servidor deveria contar com a idade mínima de 53/48 anos (homem/mulher), bem como 35/30 anos de contribuição (homem/mulher), devendo ainda prestar um tempo adicional de serviço (pedágio) de $20 \%$ do tempo que faltasse para a aposentadoria, e contar com 5 anos de efetivo exercício do cargo em que pretenda se aposentar. Todavia, este art. $8^{\circ}$ foi revogado pela EC 41/2003, que passou a regular a transição destes servidores (ingressados no serviço público antes de 16/12/1998) em seu art. $2^{\circ}$.

Com a regulação do art. $2^{\circ}$ da EC 41/2003, o regime de aposentadoria dos servidores que ingressaram anteriormente à data da publicação da EC 20/98 (16/12/1998), e que não tinham direito adquirido à aposentadoria pelo regime anterior, permaneceu praticamente o mesmo, com o detalhe de que não mais seria garantido o cálculo dos proventos de modo integral, de acordo com sua última remuneração, tendo em vista a alteração do art. $40, \S 3^{\circ}$, que passou a 


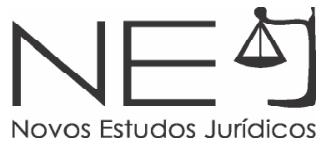

prever que seriam consideradas todas as remunerações utilizadas como base para as contribuições recolhidas ao respectivo RPPS, corrigidas monetariamente, fazendo-se então uma média de tais contribuições. Ainda, a regra de transição da EC 20/98, com a modificação da EC 41/2003, mantém o direito à paridade dos reajustes de aposentados e pensionistas com os reajustes e as vantagens deferidas aos servidores ativos, tendo em vista o art. $7^{\circ}$ da EC41/2003.

De outro lado, outra regra de transição fora instituída, para que os servidores obtivessem o direito a proventos integrais e com paridade. Trata-se do art. $6^{\circ}$ da EC 41/2003, aplicável a todos que tenham ingressado no serviço público antes da publicação da referida Emenda, pela qual o servidor deveria contar com a idade mínima de 60/55 anos (homem/mulher), bem como 35/30 anos de contribuição (homem/mulher), devendo ainda comprovar 20 anos de efetivo exercício do serviço público, 10 anos de carreira e 5 anos de efetivo exercício do cargo em que pretenda se aposentar. Entretanto, essa paridade passa a ser parcial, limitada ao valor do subsídio mensal do ministro do STF, teto do funcionalismo público (art. 37, Xl, da CF).

Ou seja, a EC 41/2003 instituiu duas regras de transição distintas, em seus arts. $2^{\circ}$ e $6^{\circ}$. Para os servidores que ingressaram antes da publicação da EC 20/98, há a opção entre uma das duas regras citadas anteriormente; para os que ingressaram entre as EC's 20/98 e 41/2003, aplicar-se-á a sistemática do art. $6^{\circ}$, caso o servidor almeje integralidade e paridade. Com isso, os servidores que ingressaram no serviço público, a partir da EC 41/2003, perderam o direito à paridade remuneratória e à integralidade dos proventos em relação à remuneração da ativa, que só foram mantidos para quem ingressou até 30/12/2003.

Por fim, após a edição da EC 41/2003, com a inclusão do $\$ 19$ ao art. 40 da Constituição Federal, aquele servidor que preencher os requisitos para se aposentar conforme o art. 40, $\S 1^{\circ}, \mathrm{III}, \mathrm{a}$, da CF, o texto da respectiva regra de transição, e optar por permanecer no serviço público, fará jus a um abono de permanência equivalente à sua contribuição previdenciária. 
Posteriormente, a EC 47/2005, em seu art. 30, estabeleceu uma nova regra de transição para os servidores que ingressaram antes de 16/12/1998, permitindo, em dispositivo mais brando que o art. $2^{\circ}$ da EC 41/2003, a concessão de aposentadoria pela regra conhecida como 95/85 pontos (95, pela soma da idade com tempo de contribuição para o servidor homem, e 85, para a servidora). Para usufruir desta regra de transição, o(a) servidor(a) terá que comprovar 25 anos de efetivo exercício do serviço público, 15 anos de carreira e 5 anos de efetivo exercício no cargo em que pretenda se aposentar. Esses novos parâmetros, por outro lado, também passaram a ser utilizados para a aplicação da regra de paridade plena dos reajustes dos proventos, conforme se percebe da revogação do parágrafo único do art. $6^{\circ}$ da EC 41/2003 e do novel parágrafo único do art. $3^{\circ}$ da EC 47/2005. Conforme o art. $6^{\circ}$ da EC 47/2005, esse art. $3^{\circ}$ da EC 47/2005 é de eficácia retroativa, para fins de proteger aqueles que se aposentaram, entre 01/01/2004 e 05/07/2005, conforme as regras mais rígidas do art. $2^{\circ}$ da EC 41/2003.

Obviamente, a reforma trazida em cada emenda constitucional permitia ao servidor requerer sua aposentadoria, optativamente, conforme a regra de transição ou conforme o texto atualizado do art. 40 da Constituição Federal (que era sempre um regime mais restritivo). A feição atual do art. 40, aplicável obrigatoriamente a todos os servidores que ingressaram no serviço público a partir de 01/01/2004, dispõe que a aposentadoria do servidor público deve ser calculada segundo a média aritmética dos valores de suas contribuições e com direito a reajustes periódicos nos mesmos moldes daqueles devidos aos beneficiários do RGPS. Ainda, o ente federativo poderá limitar as aposentadorias ao teto do RGPS do art. 201 da CF, caso institua regime de previdência complementar para seus respectivos servidores, por intermédio de entidades fechadas de natureza pública (art. 40, §§14 a 16, da CF). Esse regime começou a ser instituído com a edição da Lei 12.618/2012 (com o acréscimo do art. 92 da Lei n. ${ }^{\circ}$ 13.328/2016), seguida por decretos regulamentadores da criação dos planos de benefícios em cada entidade de previdência complementar de cada Poder, FUNPRESP-EXE, FUNPRESP-LEG E FUNPRESP-JUD. 




Com a revogação de todas estas regras de transição supratranscritas, nota-se que o relator manteve as regras de transição para a concessão de aposentadorias aos servidores públicos, na forma apresentada na proposta original, e acrescenta outra, conforme o substitutivo demonstra. Vê-se como serão as duas principais regras de transição propostas pelo relator, para os servidores públicos, na PEC 6/2019.

Há duas possibilidades de regra de transição para os servidores públicos federais, de modo geral, nos arts. $4^{\circ}$ e 20 da PEC. São requisitos comuns para as duas regras de transição: o servidor possuir 35/30 (H/M) anos de contribuições, 20 anos de efetivo exercício no serviço público e 5 anos no cargo efetivo em que se der a aposentadoria.

Para a regra de transição do art. $4^{\circ}$, o servidor ainda terá que possuir mais dois requisitos: 61/56 (H/M) anos de idade mínima e um somatório da idade e do tempo de contribuição, incluídas as frações, equivalente a 96/86 (H/M) pontos (a partir de 01/01/2020, essa pontuação será acrescida a cada ano de um ponto até atingir o limite de 105/100, e a partir de 01/01/2022, essa idade mínima será elevada para 62/57). Já para a regra de transição do art. 20, esses dois requisitos supramencionados são trocados por outros dois: 60/57 (H/M) anos de idade mínima e um pedágio de $100 \%$ do tempo que faltaria para atingir o tempo mínimo de 30 ou 35 anos de contribuição na data de entrada em vigor da EC.

Uma diferença crucial entre as duas regras dos arts. $4^{\circ}$ e 20 do texto proposto pelo relator é o fato de que as garantias de integralidade e paridade, como formas de cálculo e de reajuste dos benefícios daqueles servidores que ingressaram no serviço público até 31/12/2003, continuarão sendo devidas, desde que, na hipótese do art. $4^{\circ}$, os servidores se aposentem aos 65/62 (H/M) anos de idade, ou aos 60/57 (H/M) anos de idade, se titulares do cargo de professor; enquanto que, na hipótese do art. 20, essa idade mínima para usufruto das garantias de integralidade e paridade cai para 60/57 (H/M) anos de idade e 55/52 (H/M) para professores e professoras. 
Nos termos do art. 26 da PEC, conforme proposição do relator, os servidores que ingressaram após 31/12/2003, mas antes da implantação do regime de previdência complementar (§§14 a 16 do art. 40 da CF), terão sua aposentadoria calculada sob a média aritmética simples dos salários de contribuição e das remunerações adotados como base para contribuições ao RPPS, ou como base para contribuições decorrentes das atividades militares de que tratam os arts. 42 e 142 da Constituição Federal, atualizados monetariamente, correspondentes a 100\% do período contributivo desde a competência julho de 1994 ou desde o início da contribuição, se posterior àquela competência. Nesse caso, não haverá limitação ao teto de pagamentos do INSS; todavia, se o servidor ingressou após a implantação do regime de previdência complementar ou tenha exercido a opção pela migração de regime, o cálculo de sua aposentadoria não poderá exceder o valor máximo do salário de contribuição do RGPS. Nas duas hipóteses, entretanto, o benefício de aposentadoria corresponderá a 60\% da média aritmética definida, com acréscimo de $2 \%$ para cada ano de contribuição que exceder o tempo de 20 anos de contribuição, podendo, apenas para fins de cálculo, o período de contribuição ser desprezado caso ele resulte em benefício que lhe seja desfavorável. O que há de novo, então? Será que as novidades preservam o Estado de Direito e a segurança jurídica dos servidores que estão em vias de se aposentar?

A nosso sentir, havia violação inconstitucional ao princípio da proteção da confiança nos atos legislativos, para aqueles servidores que ingressaram anteriormente à EC 20/98 e que estão na iminência de se aposentar com idade de $53 / 48$ anos de idade $(\mathrm{h} / \mathrm{m})$, e com base na soma de idade e tempo de contribuição. Não havia justificativa adequada para se desprestigiar a expectativa legítima desses servidores, de que vissem sua segurança jurídica respeitada. O Estado de Direito estava fragilizado.

Segundo o texto original da PEC, para os que ingressaram até 31/12/2003, e não optaram pelo regime de previdência complementar, seria assegurada a integralidade da remuneração, desde que, adicionalmente, cumprissem a idade mínima de 62 anos para mulher e 65 anos para o homem, mantida a paridade 


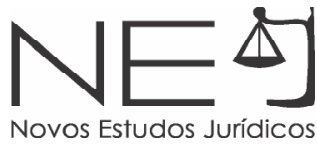

com a última remuneração do cargo para fins de reajuste dos benefícios, mas apenas se forem observadas essas idades mínimas. Em nosso sentir, também nessa hipótese normativa nova não havia qualquer respeito constitucional à segurança jurídica com essa disposição, pois nunca se exigiu idade mínima para o usufruto do direito à integralidade e à paridade. Dessa forma, o Estado não poderia romper com as normas até então vigentes, sem qualquer justificativa adequada. Os direitos à integralidade e à paridade não poderiam ser abruptamente condicionados, de modo mais gravoso, a servidores que expectavam se aposentar, aproximadamente, aos 53/48 anos (que ingressaram antes da EC 20/98), ou aos $60 / 55$ anos (que ingressaram entre a EC 20/98 e a EC 41/2003). Como poderia ser exigido que usufruíssem desses direitos apenas com 65/62 anos?

Todavia, com o texto apresentado pelo deputado-relator, as garantias de integralidade e paridade podem ser obtidas com uma idade menor (60/57 anos), desde que prestado o tempo do pedágio, o que pode indicar uma ausência de razoabilidade do pedágio, especialmente para quem tem mais de 10 anos de contribuição a cumprir. Nessas hipóteses, o interessado se veria na iminência de um pedágio inviável de ser cumprido, indicando que a regra definitiva seria a aplicável ao caso. A discussão, portanto, passa pela razoabilidade de uma regra de transição desse patamar.

Por fim, é preciso anotar que há maior medida de justiça na regra de transição do art. 20 da PEC para servidores que estejam próximos da data de se aposentarem, bem como a relevância de se juntar o maior tempo possível de contribuição para possibilitar um pedágio menor, especialmente para servidores que possuam o direito à integralidade e à paridade e que tenham tempo de contribuição anterior ao ingresso no serviço público; nesses casos, os servidores que antes completariam os requisitos para a aposentadoria com uma idade menor (especialmente aqueles que ingressaram no serviço público antes da EC 20/98) agora terão que aguardar ao menos até os 60/57 anos de idade, para implementarem os requisitos e poderem ter acesso ao abono/aposentadoria. 


\section{CONSIDERAÇÕES FINAIS}

Quanto à problemática da segurança jurídica devida aos trabalhadores filiados aos sistemas de previdência em face de alterações legislativas mais restritivas, o Supremo Tribunal Federal persiste em prestigiar um pensamento doutrinário insustentável. Levado em suas últimas consequências, põe em salvaguarda apenas os direitos adquiridos e a justificação para tanto é por demais simplória: inexistência de direito adquirido a regime jurídico.

Ocorre que a máxima jurisprudencial da inexistência de direito adquirido a regime jurídico não implica negar qualquer grau de tutela jurídica aos direitos em formação, em observância aos princípios da proteção da confiança e da boafé objetiva, os quais emprestam forma à segurança jurídica, fundamento de um Estado Constitucional de Direito. Como já se sustentou alhures, a insistência na anacrônica dualidade direito adquirido/expectativa de direito também parece convergir com uma racionalidade finalística das principais decisões judiciais da Suprema Corte em tema de direitos sociais, a qual se expressa, de forma clara, em um consequencialismo utilitarista de extração econômica ${ }^{35}$. Deve-se ter em mente, porém, que a ausência de direito transitório razoável, em nome de um utilitarismo de eficiência do sistema, não afeta apenas as posições jurídicas de um indivíduo e a confiança que este emprestou à ordem jurídica.

Na visão de José Adércio Leite Sampaio, "há em jogo uma fidúcia ínsita à validade de um contrato muito mais importante do que a quase totalidade dos contratos, porque é uma espécie de acordo entre gerações" ${ }^{36}$ O que não parece admissível é a simples aplicação da "fórmula dogmática de direito

35 Sobre isso, conferir: SAVARIS, José Antonio. Uma teoria da decisão judicial da Previdência Social: contributo para a superação da prática utilitarista. Florianópolis: Conceito, 2011.

36 E acrescenta o mestre mineiro, traduzindo precisamente o sentimento de insegurança daqueles que se forçam a depender do sistema previdenciário: "Que consideração a atual geração teve com a passada para garantir que no futuro se possa contar com a mesma ou pior consideração? Quem pode acreditar no futuro e numa velhice digna, princípio igualmente constitucional, se as regras do jogo mudam com o jogo e constantemente? Que pós-modernismo é esse, da estabilidade instável das rules of the living games, que funciona apenas de um lado - contra o mais fraco? Por que acreditar em promessas constitucionais? O que está em jogo é muito mais do que vínculos previdenciários; é o próprio sentimento ou patriotismo constitucional, base de toda arquitetura social e política, base de todo futuro de parceria comunitária. Os argumentos, em forma de interrogantes, não são elementos extrajurídicos que não entram em consideração jurídica, mas traços e topoi que se apresentam para o diálogo com o intérprete judicial". SAMPAIO, José Adércio Leite. Expectativa de Direito e Direito Adquirido como Franquias e Bloqueios da Transformação Social. In ROCHA, Carmen Lúcia Antunes (Org.). Constituição e segurança jurídica: direito adquirido, ato jurídico perfeito e coisa julgada. Estudos em homenagem a José Paulo Sepúlveda Pertence. $2^{\text {a }}$ edição, Belo Horizonte, p. 314. 




intertemporal" (proteção jurídica apenas dos direitos adquiridos), pois ela pode trazer injustiça concreta.

Em última análise, a alteração a cada tempo - ou a cada crise fiscal - dos parâmetros normativos para a concessão de aposentadorias voluntárias, com a absoluta desconsideração de regras transitórias anteriormente estabelecidas, consubstancia frustração de expectativas firmadas por longos períodos de tempo e situação de incerteza jurídica inaceitável, a ponto de ninguém mais poder afirmar, com razoável segurança, quando ou se um dia adquirirá o direito previdenciário que constitucionalmente lhe fora prometido.

Portanto, propiciar igualdade e defender a eficácia de fatos realizados em regimes legais anteriores, mas ainda não consumados, deve ser uma preocupação presente em qualquer debate sobre segurança jurídica e direito adquirido. E é nesse ponto que reside uma importante lacuna da nossa dogmática constitucional.

\section{REFERÊNCIA DAS FONTES CITADAS}

ARAÚJO, Valter Shuenquener de. O princípio da proteção da confiança: uma nova forma de tutela do cidadão diante do Estado. $2^{\text {a }}$ Ed. Niterói: Impetus, 2016.

BARROSO, Luís Roberto. Curso de Direito Constitucional Contemporâneo. $7^{\text {a }}$ Ed. São Paulo: Saraiva Educação, 2018.

CAMPOS, Marcelo Barroso Lima Brito de. Direitos previdenciários expectados: a segurança na relação jurídica previdenciária dos servidores públicos. Curitiba: Juruá, 2012.

CANOTILHO, José Joaquim Gomes; MOREIRA, Vital. Constituição da República Portuguesa Anotada. Volume I, 4a Ed. Coimbra: Coimbra Editora, 2007.

GILLION, Colin et al. Pensiones de Seguridad Social, Desarrollo y reforma, Informes OIT, $n$. 57, Madrid: Ministerio de Trabajo y Asuntos Sociales, 2002, pp. 384-388.

NEVES, llídio das. Crise e Reforma da Segurança Social. Equívocos e Realidades, Lisboa: Edições Chambel, 1998.

RÁO, Vicente. $\mathrm{O}$ direito e a vida dos direitos. $5^{\mathrm{a}}$ Ed. Anotada e atualizada por Ovídio Rosa Barros Sandoval. São Paulo: Revista dos Tribunais, 1999.

RIBEIRO, Ricardo Lodi. A segurança jurídica do contribuinte: legalidade, não-surpresa e proteção à confiança legítima. Rio de Janeiro: Lumen Juris, 2008. 
SAMPAIO, José Adércio Leite. Expectativa de Direito e Direito Adquirido como Franquias e Bloqueios da Transformação Social. In ROCHA, Carmen Lúcia Antunes (Org.). Constituição e segurança jurídica: direito adquirido, ato jurídico perfeito e coisa julgada. Estudos em homenagem a José Paulo Sepúlveda Pertence. $2^{a}$ edição, Belo Horizonte: Fórum, 2005, p. 265-343.

SARLET, Ingo Wolfgang. A eficácia do direito fundamental à Segurança Jurídica: dignidade da pessoa humana, direitos fundamentais e proibição de retrocesso social no direito constitucional brasileiro. In ROCHA, Carmen Lúcia Antunes (Org.). Constituição e segurança jurídica: direito adquirido, ato jurídico perfeito e coisa julgada. Estudos em homenagem a José Paulo Sepúlveda Pertence. 2a edição, Belo Horizonte: Fórum, 2005, p. 85-135.

SARLET, Ingo Wolfgang. O Estado Social de Direito, a Proibição de Retrocesso e a Garantia Fundamental da Propriedade. Revista Diálogo Jurídico, Salvador, CAJ - Centro de Atualização Jurídica, v. I, n. 4, julho, 2001. Disponível em: <http://www.direitopublico.com.br>. Acesso em: 20 de fevereiro de 2006, p. 8.

SAVARIS, José Antonio. Direito Processual Previdenciário. 8ª Ed. Curitiba: Alteridade, 2018.

Uma teoria da decisão judicial da Previdência Social: contributo para a superação da prática utilitarista. Florianópolis: Conceito, 2011.

SILVA, José Afonso da. Comentário contextual à Constituição. $3^{a}$ Ed. São Paulo: Malheiros, 2007.

SOUZA, Victor. Proteção e Promoção da Confiança no Direito Previdenciário. Curitiba: Alteridade, 2018.

STAFFEN, Marcio Ricardo; ARSHAKYAN, Mher. The legal development of the notion of human dignity in the constitutional jurisprudence. Revista Brasileira de Direito, Passo Fundo, v. 12, n. 2, p. 108-126, dez. 2016. 